IBIMA Publishing

Journal of Eastern Europe Research in Business and Economics

http://ibimapublishing.com/articles/JEERBE/2018/336800/

Vol. 2018 (2018), Article ID 336800, 7 pages, ISSN: 2169-0367

DOI: $10.5171 / 2018.336800$

Research Article

\title{
Adaptation of Employees of the Regional Authorities: Areas for Improvement
}

\author{
Elena Kolesnichenko ${ }^{1}$, Yana Radyukova ${ }^{2}$ and Dmitry Kolesnichenko ${ }^{3}$ \\ ${ }^{1,2}$ Tambov state university named after G.R. Derzhavin, Tambov, Russia \\ ${ }^{3}$ Department of physical training Ryazan Branch of the Kikot Moscow \\ University of the Ministry of Internal Affairs of Russia, Ryazan, Russia
}

Correspondence should be addressed to: Elena Kolesnichenko; ekolesnichenko@live.ru

Received date: 15 February 2018; Accepted date: 05 June 2018; published date: 31 July 2018.

Academic Editor: Olga Kalinina

Copyright (C 2018. Elena Kolesnichenko, Yana Radyukova and Dmitry Kolesnichenko

. Distributed under Creative Commons CC-BY 4.0

\begin{abstract}
Topicality: in the modern conditions of management, special attention is paid to improving the effectiveness of personnel management, which is especially important for regional authorities, because the effectiveness of the social and economic development of the entire territory depends on the managerial decisions they make. The adaptation of the staff has a direct impact on the effectiveness of the professional activities; however, many managers underestimate this important process. Studies show that in many organizations this process is spontaneous; there are no basic programs for the adaptation of employees. However, the competent organization of the adaptation process influences the way the employees do their professional duties; the way they associate themselves with the company; and the way they accept its norms and values. The aim of the research is to theoretically substantiate and develop directions for improving the process of adaptation of state civil servants. The object of the study is the work of the employees of the regional legislative bodies. Methods of research: the basis of the study was a systematic approach to the management of staff adaptation, monographic research method, questioning, interviews, and surveys. Results of research. While doing the research, the authors analyzed the most frequently encountered problems in the sphere of adaptation management. The conducted questioning of the employees of the regional legislative bodies showed that the greatest difficulty in the adaptation period is experienced by new employees in the performance of professional duties, joining a new work-team, and they also had some problems connected with the specifics of public service. Both experienced and young specialists had such difficulties. The authors determine the factors that have an impact on the course of adaptation of employees and their job satisfaction, which affects their adaptation in the work place. The interview and the survey conducted with the experienced specialists of the regional legislative bodies made it possible to reveal the level of their organizational skills, team orientation, the desire to share their knowledge and experience, the degree of tolerance and psychological stability. Conclusions: referring to the study and analysis of the adaptation of the employees of the regional legislative bodies, we developed a Draft Regulation on the adaptation of employees and directions for improving the management of the adaptation of public civil servants of the regional legislative bodies.
\end{abstract}

Keywords: labor adaptation, adaptation system, adaptation process, adaptation methods, adaptation program, mentoring.

Cite this Article as: Elena Kolesnichenko, Yana Radyukova and Dmitry Kolesnichenko (2018)," Adaptation of Employees of the Regional Au-thorities: Areas for Improvement", Journal of Eastern Europe Research in Business and Economics, Vol. 2018 (2018), Article ID 336800, DOI: 10.5171/2018.336800 


\section{Introduction}

Today, there are several approaches to the interpretation of the concept of staff adaptation. L.N. Ivanova-Shvets defines the adaptation of personnel as a mutual adaptation of the worker and organization. In the opinion of A.P. Egorshina, labor adaptation - is the adaptation of the employee to the team and the new place of work. N.I. Makarenko points out that the adaptation of personnel should be seen as an active mastering of social and professional functions by the employee by overcoming certain negative aspects that can arise both through the fault of the employee and through the fault of the organization. V.R. Vesnin believes that adaptation means the adaptation of the employee to a new social environment, the conditions and the content of labor. According to A.Ya.Kibanov, adaptation is a mutual adaptation of the worker and organization, which is based on the gradual employee training in new professional, social and organizationaleconomic working conditions [4].

The course, pace and results of adaptation are influenced by many factors (Fig. 1).

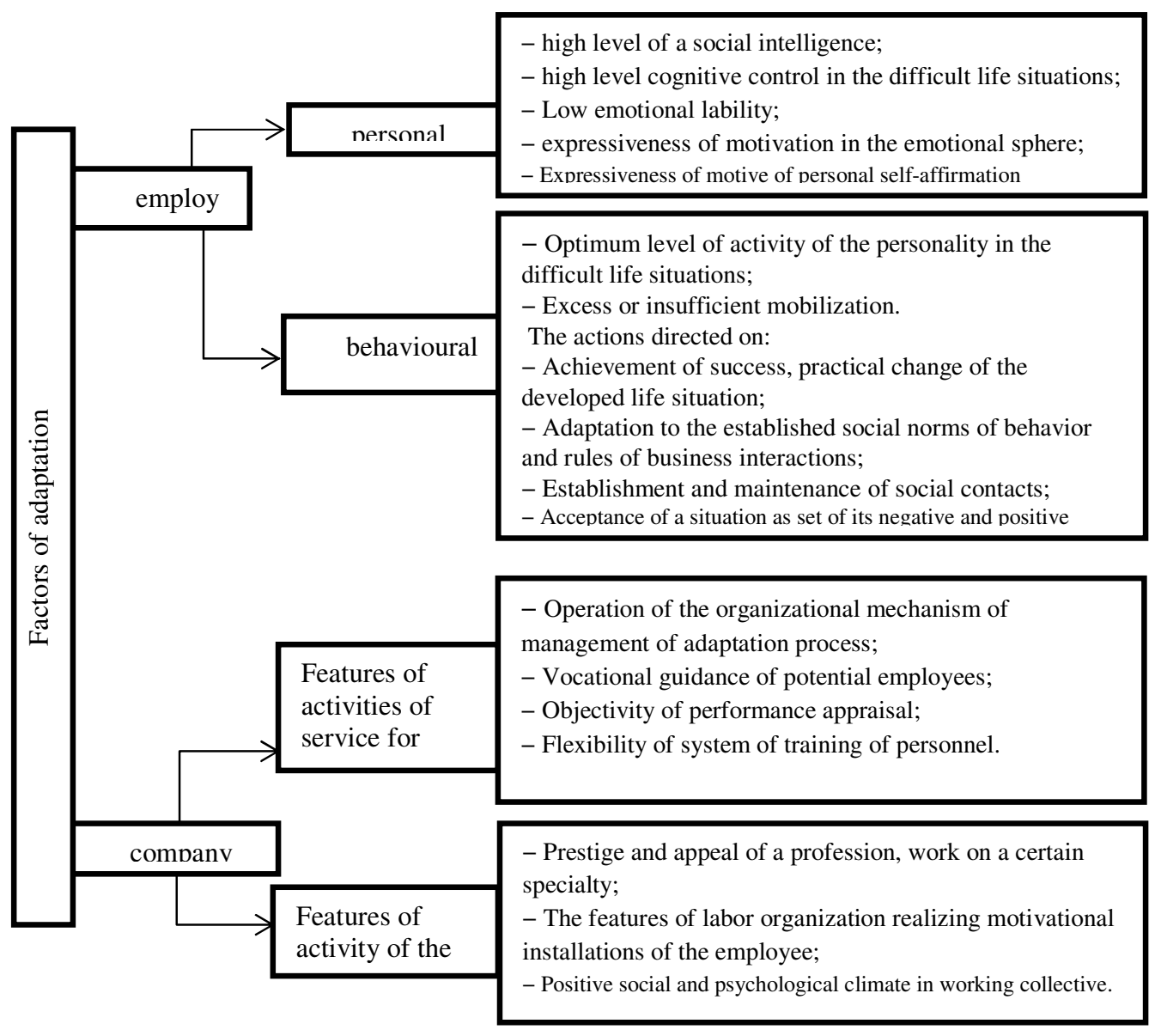

Figure 1: Factors affecting the process of staff adaptation 


\section{Methods}

Specificity of adaptation in the regional authorities was studied on the example of state civil servants in the regional Duma. To achieve these objectives, first of all, the normative documents were studied, namely the job descriptions of employees of the civil service and personnel department, the regulations of the regional Duma, the Regulations on the Civil Service Department and the staff of the regional Duma.

During the probation period, regular conversations were conducted with the employees in order to find out the way their development took place in a new place, whether they had any problems, whether they needed anything or not. Also we worked with the team. Its goal was to help the newcomer in terms of social adaptation, adaptation to the team, the provision of communication.

At the third stage, a questionnaire was conducted with the staff of the Duma. To study the features of adaptation, both young and experienced specialists were selected. The questioning was aimed at identifying the specifics of the adaptation period of young and experienced employees. The results of the questionnaire were to show the presence of common and different moments in the course of the adaptation process among young and experienced employees, as well as problems that arose during this period. Employees of various departments of the regional Duma took part in the survey, since each of them had a certain focus and a different nature of the work, there were 11 people in total: 5 young professionals ( 2 men and 3 women) and 6 experienced employees (5 women and 1 male).
In addition to the questionnaire, which was aimed at identifying key problems faced by new specialists during the adaptation in the regional Duma, a mini-survey was conducted among young professionals working for up to one year. They were young employees aged 20 to 25 years. The main task of the survey was to find out the way professional, organizational, psychophysiological and socio-psychological adaptations took place, and what we had to pay attention to when working with each individual employee.

\section{Results and Discussion}

During the analysis of the above-mentioned documents, it was noted that in the "Regulations ..." the adaptation of employees was not singled out as a separate function, respectively, the persons responsible for conducting it were not specified. Also in the regional Duma there is no separate Regulation on adaptation, in which the timing of the adaptation, the persons responsible for it, the plan of measures, etc., would be fixed. Despite this, in fact, the adaptation of new employees is carried out. As a rule, the head of the department, the immediate supervisor, is engaged in the adaptation of civil servants, and the head of the apparatus of the regional Duma supervises the course of adaptation. From the beginning of the new employee's work activity, the head of management in which he/she works provides all the necessary documents: instructions for working with documents in the regional Duma, Regulations on committees in the regional Duma, Regulations of the regional Duma, federal laws that need to be guided in their activities. The results analysis of the questionnaire showed that among the main problems that arose during the period of adaptation, the employees distinguished the following: professional duties, joining a new team, peculiarities of work in the civil service (Figure 2). 


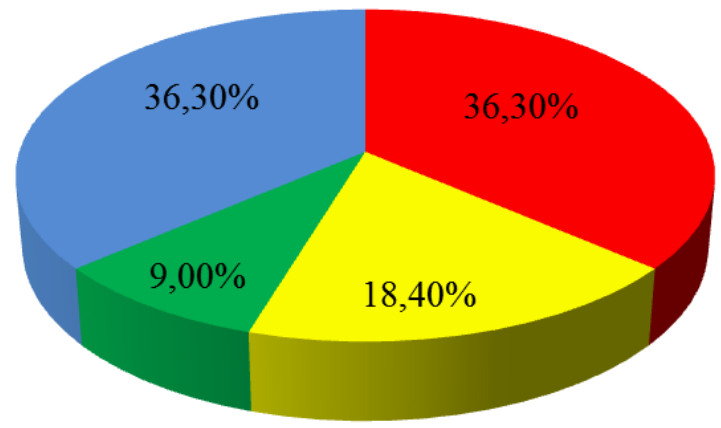

\author{
professional duties \\ inclusion in collective \\ features of work \\ in public service \\ n there were no problems
}

Figure 2: The proportion of problems that caused the greatest difficulties for the employees in the course of adaptation

If we consider gender differences, it can be seen from the diagram that the performance of professional duties caused the difficulty mainly in women, while in men - to a lesser extent. Also, women had problems connected with joining a new team: men do not notice such problems. For one of the interrogated men, transition to a public authority caused the difficulty (Figure 3).

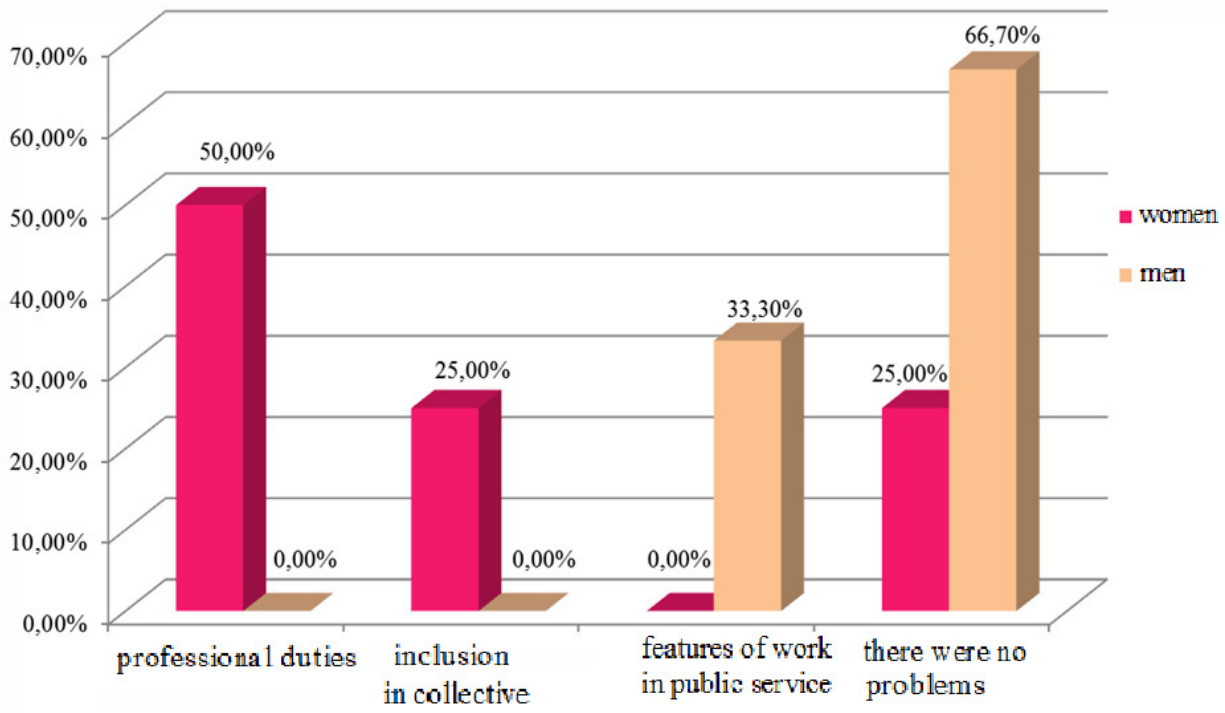

Figure 3: Gender differences in the proportion of problems that caused the greatest difficulties in the adaptation process for the youngest employees

Comparing the answers of young and experienced employees, it should be noted that they had identical problems, but caused by different reasons. If for specialists with experience difficulties in joining the team were conditioned by adaptation and habit to the previous one, for young specialists without work experience, work in the team was a completely new stage, which required mobility, mastering the rules of communication, tolerance, etc.

Analyzing the respondents' answers about the adaptation time, it was noted that the male needed less time to adapt (up to two months on average) than women (four to five months on average). This tendency can be attributed to the fact that men are more psychologically stable, and immediately try 
to get involved in the work, for women it is important at the initial stage of adaptation to adapt to the team, as well as building relationships with new colleagues. Consequently, the process of adaptation is somewhat delayed. This suggests that men are able to adapt in a shorter time and less painfully.

Important points are that 9 out of 11 respondents indicate their colleagues as people who assisted with adaptation, and only 2 people mention the direct leader. We should point out the fact that out of 11 people 9 have never thought about changing jobs in the first months of work, although, as a rule, it is during this period that new employees are inclined to such thoughts. This fact indicates that specialists have a high degree of loyalty to the organization from the first months of work.

The results of the mini-survey show that the best way for young professionals is psychophysiological adaptation, we can say that it has already been completed. All employees quickly adapted to the mode of work, work schedule and assess the working conditions as excellent ones. Professional adaptation has not yet been completed, as employees need time for full inclusion in the work process. As for the socio-psychological and organizational adaptation, there are a number of problems. The majority of respondents noted that they were only partially acquainted with the structure of the regional Duma and did not receive any explanation about what place their division occupied in the general structure. Also 4 out of 5 employees were not fully aware of their role in the management activities during the first month of work. Considering the socio-psychological aspect of adaptation, it should be noted that 4 out of 5 specialists in general share the norms and values adopted in the Duma, but they have their opinion on a number of issues; 2 people out of 5 found a common language with all colleagues, and 3 people feel comfortable not with all members of the team. Despite this, $90 \%$ of civil servants do not regret that they work in the regional Duma. This suggests that, despite the problems faced by young professionals, they have an incentive to move forward.

\section{Conclusions}

The study revealed that the course of adaptation was influenced by a number of different well-known factors, such as:

- the content of labor;

- the position held;

- compliance of work with the specialty;

- compliance of qualifications with work;

- $\quad$ conformity of the nature of work with inclinations and abilities;

- availability of career prospects;

- $\quad$ possibility of further training;

- wages;

- Relations with the direct supervisor, etc.

Satisfaction with these factors positively or negatively affects the adaptation of the employee [6]. Our task was to find out if the experts whose adaptation had not yet been completed were satisfied with the above factors. This information will help to find out in which area the new employees usually have problems in the adaptation period and what is needed for the manager, mentor and civil servant staff to focus on the adaptation plan.

It was revealed that new employees experience the greatest difficulty in the adaptation period when performing professional duties, joining a new team, which is due to various reasons (change of job, differences in requirements for positions, etc.). It should be noted that for young professionals, socio-psychological, professional and organizational adaptations take place with complications, what is important to pay attention to.

According to the results, the research identified the main problems that new specialists faced in the first months of work. We found out that both the young specialists and the experienced ones noted difficulties arising at the beginning of their work in the regional Duma, the performance of their professional duties and joining the team. In the course of the survey with young specialists working for less than a year (adaptation of some of them has not yet been 
completed), it was found out that the most successful were the socio-psychological and psychophysiological adaptations, while the professional and organizational ones cause difficulties. In this regard, some recommendations have been developed that include a plan of adaptation measures for facilitating the adaptation process for public civil servants.

Recommendations for implementing sociopsychological adaptation:

- $\quad$ arrange the acquaintance of the new employee with the team. Acquaintance should take place in the form of a dialogue, rather than simply presenting a new employee to the team;

- conduct a conversation with a newcomer, the purpose of which will be to identify the wishes of the young specialist. Also during the conversation you can find out what is most difficult for the employee during the adaptation period;

- $\quad$ entrust a new employee with a task together with colleagues, in order to identify with whom he/she is better at interacting with;

- arrange "dedication" of a new specialist, to make it clear that he/she is already important to the company and is a full-fledged employee.

Recommendations for professional adaptation:

- $\quad$ assign a young staff member to a mentor who will assist the employee during the adaptation period and monitor it. The tutor should familiarize the employee with the adaptation program and its expected terms;
- $\quad$ prepare a "novice folder" i.e. a certain brochure in which the answers to the questions, that the new employee will most often have, must be collected [5] for the employee;

- give the employee an individual task, during which he/she will be able to demonstrate his/her professional abilities and skills, as well as find out what direction in the professional sphere the specialist is most interested in, listen to his/her wishes and suggestions, if necessary, provide additional information on the issues;

- conduct a conversation with the employee and find out what problems he/she has in terms of professional adaptation, how serious they are, what he/she thinks they are related to and how the employee himself/herself finds the way to solve them.

Recommendations for organizational adaptation:

- provide the specialist with information on the organizational structure and clearly describe the functions of each unit and their place in the entire management structure;

- if the specifics of the organization's activities, in which the specialist worked before, differ from the activities of the regional Duma, it is necessary to familiarize the new employee with the main areas of activity, to emphasize the nature of the work of the legislative authority [8].

There were some ways to neutralize the factors that employees are not satisfied with or the assessment of which is in doubt, proposed, to prevent the dissatisfaction with these aspects from having a negative focus (Table 1). 
Table 1: Recommendations for optimizing the factors that could adversely affect the adaptation process

\begin{tabular}{|l|l|}
\hline \multicolumn{1}{|c|}{$\begin{array}{c}\text { The problem } \\
\text { factor }\end{array}$} & \multicolumn{1}{c|}{ Ways of solution } \\
\hline $\begin{array}{l}\text { 1. Prospects for } \\
\text { development }\end{array}$ & $\begin{array}{l}\text { - invite employees to participate in the preparation for the Duma meeting } \\
\text { as an aid to other departments; } \\
\text { - expand the area of responsibility of employees, provide an opportunity to } \\
\text { perform tasks of a more complex level; } \\
\text { - more often assess the staff, which will reveal the level of the } \\
\text { competencies, both professional and personal ones; }\end{array}$ \\
\hline $\begin{array}{l}\text { 2. Possibility of } \\
\text { advanced } \\
\text { training }\end{array}$ & $\begin{array}{l}\text { - periodically organize various training courses, taking into account specific } \\
\text { positions, experience of specialists; } \\
\text {-cooperate with centers of training and advanced training; } \\
\text { - develop and implement training programs. }\end{array}$ \\
\hline $\begin{array}{l}\text { 3. Labour } \\
\text { organization }\end{array}$ & $\begin{array}{l}\text { - carry out diagnostics and identify specific factors of dissatisfaction; } \\
\text { - pay attention to the organization of the work process (time of work and } \\
\text { rest); } \\
\text { - properly organize the process of interaction between units; } \\
\text { - equip workplaces in accordance with the specific requirements of } \\
\text { employees. }\end{array}$ \\
\hline 4. Wages & $\begin{array}{l}\text { - discuss together with employees their claims to wages and analyze in } \\
\text { detail the process of its accrual (for what types of work) [7]; } \\
\text { - offer employees additional workload. }\end{array}$ \\
\hline
\end{tabular}

These recommendations will help reduce the frustration of employees, which will help them take a step forward towards full adaptation.

\section{References}

1. Vesnin, V.R. (2010) Management, Moscow: Prospekt, 245 p.

2. Egorshin, A.P. (2015) Human resource management, Moscow: Infra-M, 215 p.

3. Ivanova-Shvets, L. N. (2008) Human resource management, Moscow: EOI publishing center, $115 \mathrm{p}$.

4. Kibanov, A.Ya. (2007) Human resource management of the organization, Moscow: Infra-M. 311 p.

5. Kobtseva, E.N. (2008) Adaptation of personnel: classification of types and indicators, Bulletin of VSU. Series: Economy and management, No. 1, pp 101-102.

6. Kolesnichenko, E., Radyukova, Ya., Bespalov, M. (2017) Increasing the involvement of staff in the activity of the company as a factor influencing its efficiency, 30th IBIMA Conference, 8-9
November 2017, Madrid Spain, pp 21702179.

7. Kolesnichenko, E.A., Radyukova, Ya.Yu., Pakhomov, N.N. (2017) Improvement of the system of benefits and compensations in the system of implementation of the social politics of the organization, International Research Journal, No10(64), URL: https://researchjournal.org/economical/sovershenstvovani e-sistemy-lgot-i-kompensacij-v-sistemerealizacii-socialnoj-politiki-organizacii/

8. Lachugina, Yu.P. (2009) Adaptation of employees in the organization, Ulyanovsk, $11 \mathrm{p}$.

9. Makarenko, N.I. (2009) Human resource management bases, Tomsk, $75 \mathrm{p}$.

10.Filippov, S.V. (2006) Professional adaptation of graduates of tourist higher education institutions in the conditions of tourist firm, Moscow, $171 \mathrm{p}$. 